\title{
Risk Sharing in a Politically Divided Monetary Union
}

\author{
David Parsley $^{1}$ (D) $\cdot$ Helen Popper ${ }^{2}$
}

Accepted: 16 March 2021 / Published online: 7 April 2021

(C) The Author(s) 2021

\begin{abstract}
We document stark asynchronicity across U.S. states, particularly across groups of states whose populations have voted consistently Democrat or consistently Republican in national elections; and we show that the risk-sharing channels of these groups of states differ substantially. However, we find that these groups of stateseven swing states, where the role of fiscal flows is small (on par with Europe's)-do share risk. Indeed, we halve previous estimates of states' residual risk by using new data to account for sharing risk through changes in population, prices, and durable goods consumption. These findings indicate that political differences alone do not themselves preclude macroeconomic risk sharing within a monetary union.
\end{abstract}

Keywords Monetary union - Optimal currency area - Currency union · Political division

JEL Classification F33 - F45

\section{Introduction}

Clashing political preferences, along with concerns over migration and fiscal transfers, raise questions about how macroeconomic risks are now able to be shared within a monetary union. Do political divisions themselves stand in the way of economic integration within a monetary union? Do they prevent member states from sharing risk? This paper addresses these questions by focusing on the United States. Specifically, we ask: is the United States still an example of a successful monetary union despite its own notable political divisions?

David Parsley

david.c.parsley@ vanderbilt.edu

Helen Popper

hpopper@scu.edu

1 Owen Graduate School of Management, Vanderbilt University, Nashville, TN, USA

2 Department of Economics, Santa Clara University, Santa Clara, CA, USA 
To answer this question, we quantify states' economic asynchronicity and risk sharing over the recent decades; and we assess the differences across groups of states' with notably different voting patterns. To be clear, our goal here is not the identification of the effect of political differences on economic differences in the face of obvious endogeneity. ${ }^{1}$ Instead, our goal is to determine whether and how risk sharing survives amid political differences. ${ }^{2}$ This determination is critical for assessing the viability of monetary unions, ${ }^{3}$ such as-most notably-the Euro Area, where political differences such as those observed in the United States are also apparent. ${ }^{4}$

Our examination of risk sharing within the United States uses newly available, comprehensive data from the Regional Economic Accounts of the U.S. Bureau of Economic Analysis (BEA) on personal consumption expenditures by state. The new data resolve misgivings about previous, related work that could only use retail sales data to measure consumption. New data also allow us to examine the role of risk-sharing channels not yet explored year-by-year within the United States. Specifically, we quantify the extent of risk-sharing that occurs through interstate migration, through price changes, and through consumers' purchases of durable goods. ${ }^{5}$ In addition to exploring these new channels, we use the BEA consumption data to reexamine the important fiscal and financial channels studied with only retail sales data in the past, and to assess how these and the other channels differ where political preferences differ.

We document that states' GDPs are quite asynchronous, and the GDPs of states whose populations vote consistently Democratic (Blue states) and those whose populations vote consistently Republican (Red states) are particularly asynchronous: in terms of GDP changes, the Blue states and Red states look as distinct as two sovereign countries. At the same time, we observe that output asynchronicity within the United States provides an opportunity for risk sharing, but the mixture of channels used for

\footnotetext{
${ }^{1}$ Numerous authors have explored how U.S. voting outcomes are linked to purely economic differences, as well as differences in demographics, family structure, education, and health. See, for example, Glaeser and Ward (2006), Gelman et al. (2010), and Carbone and Cahn (2010). See also Cornaggia et al. (2020) who document differences across Blue and Red states in credit analysts' home biases, and Bachmann et al. (2019) who document differences in inflation expectations across Blue and Red states.

${ }^{2}$ In Appendix B, we also report differences in how risk is shared by groups of states constructed using income designations, and how it is shared by groups of states constructed using rural and urban designations.

${ }^{3}$ In his classic contribution on optimal currency areas, Mundell (1961) explains how heterogeneous economic structures imply idiosyncratic shocks; and, without sufficient channels for risk sharing, the corresponding asynchronicity undermines a currency or monetary union. That is, a monetary union imposes a single monetary policy (though, as emphasized by Rodríguez-Fuentes and Dow (2003) and by many others after the Great Recession, the effects of that single policy may vary across regions). If the members' economies differ considerably, the single policy is only workable if other channels exist to sufficiently smooth out the differences among the members' economies.

${ }^{4}$ Alesina et al. (2017) compare the political differences within the United States to those within Europe (or at least the EU 15 countries) and-perhaps surprisingly-find substantial similarities in internal political differences.

${ }^{5}$ Here, we use changes in population as an indicator of migration; this follows (Asdrubali et al. 1996), who augmented their work by using census data to explore the role of migration; however, because the census data were only available by decade, they were precluded at the time from exploring the role of population changes in smoothing consumption year by year, as we do here.
} 
risk-sharing differs across the color designations. Finally, we find that the additional risk-sharing channels that we explore are meaningful ones for the country as a whole: together, they cut previously documented unshared idiosyncratic risk in half.

Overall, our findings indicate that-despite its own internal political and economic divisions, including differences in how risk sharing is achieved-the United States still provides a benchmark of integration within a monetary union. The stark political differences between the Blue and Red states show up just as starkly as economic differences, but their differences do not stand in the way of substantial, though heterogeneous, risk sharing through various channels. While we examine only the United States, the single case demonstrates that GDP asynchronicity and even substantial political divisions are not by themselves impediments to a successful monetary union even where the role fiscal flows is small. ${ }^{6}$

Our work proceeds in three steps. We begin with a simple assessment of the extent of inter-state asynchronicity within the United States in Section 2. Then, in Section 3, we use the newly available consumption data to look at income and consumption together to examine the extent of consumption smoothing. Finally, in Section 4, we examine how consumption risk is shared across the states.

\section{GDP Synchronicity}

This section assesses the extent to which the GDPs of the states move together within the United States. ${ }^{7}$ We begin by looking at all of the states, then we look separately at groups of states that we define based on states' voting patterns. We focus on states, rather than counties (despite intra-state heterogeneity) because states correspond most naturally to the country boundaries of other monetary unions (such as the Euro Area), because states map comprehensively into Congressional representationwhich affects federal tax and transfer flows, and because they have the most complete consumption data for use in assessing risk sharing, which we examine in subsequent sections. Note that the synchronicity or asynchronicity of states, like that of countries, reflects size, industrial make up, and a host of other characteristics that (appropriately) are not controlled for. To condition on such attributes in measuring synchronicity would be to abstract from the very differences that determine countries' or states' suitability for sharing the same monetary policy.

Here, we characterize states' GDP synchronicity using the negative of the absolute difference in states' GDP growth rates. While there are many possible approaches to characterizing synchronicity, this method is straightforward, it is feasible even when the length of the time series is modest, and it is unaffected by the volatility

\footnotetext{
${ }^{6}$ In the context of monetary union, the political differences across Europe remain of particular interest. While the scope for fiscal smoothing across political divisions within Europe remains more circumscribed than within the United States, we find that fiscal smoothing is not a prerequisite to risk sharing: U.S. risk sharing occurs even in states where the smoothing role of fiscal flows is on par or even much smaller than within Europe: in swing states, poor states and rural states.

${ }^{7}$ GDP comovement is among the classic criteria used to evaluate the optimality of a currency or monetary union, but it is not a necessary condition for optimality. We take this up in Section 3.
} 


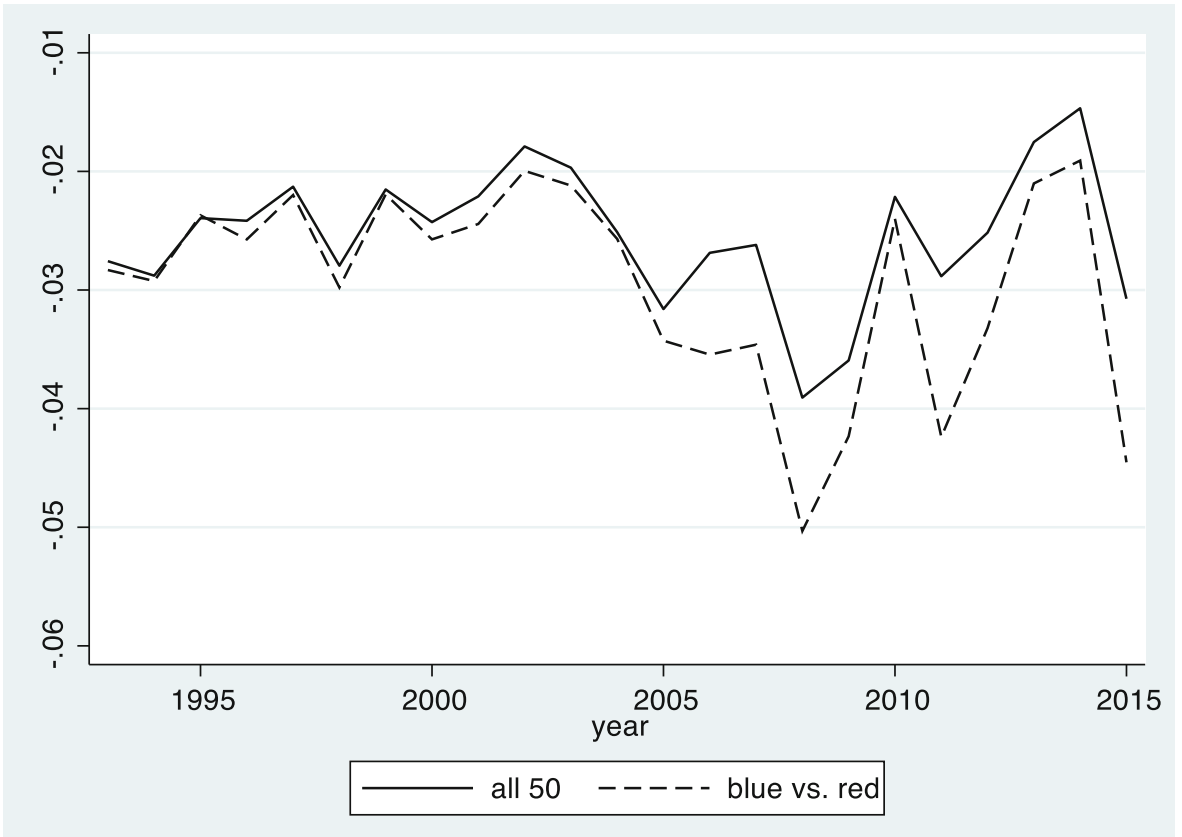

Fig. 1 State GDP synchronicity. Note: As illustrated here, greater synchronicity, $\psi_{i, j, t}$, is indicated by a higher numerical value (a smaller magnitude) of the average value of $\psi_{i, j, t}=-\mid\left(\ln Y_{i, t}-\ln Y_{i, t-1}\right)-$ $\left(\ln Y_{j, t}-\ln Y_{j, t-1}\right) \mid$, where $i$ and $j$ are defined within the relevant groupings

of output. ${ }^{8}$ Specifically, we adapt the approach of Kalemli-Ozcan et al. (2013), who examine GDP synchronicity across countries, to comparably define synchronicity among states as follows:

$$
\psi_{i, j, t}=-\left|\left(\ln Y_{i, t}-\ln Y_{i, t-1}\right)-\left(\ln Y_{j, t}-\ln Y_{j, t-1}\right)\right|,
$$

where $Y_{i, t}$ and $Y_{j, t}$ are the GDPs of the $i^{t h}$ and $j^{t h}$ states in year t. The measure becomes more negative when GDPs between two states are less synchronised.

Figure 1 shows in black the average in each year of this U.S. measure of state synchronicity from 1993 through 2015. U.S.-wide state synchronicity declined substantially in the mid-2000s until the great recession, when the state economies slowed together, then began briefly to recover together. Most recently, asynchronicity has prevailed.

Over the period as a whole, the average asynchronicity in bilateral GDP growth rates is about 2.5 percent. ${ }^{9}$ This number can be put into perspective by comparing it with synchronization measures for international economies. Kalemli-Ozcan et al.

\footnotetext{
${ }^{8}$ The importance of robustness with respect to output volatility was emphasised by Doyle and Faust (2005) even before the Great Recession. Kalemli-Ozcan et al. (2013) also point out that the asynchronicity measure used here is robust to various filtering methods. Kalemli-Ozcan et al. (2013), in turn, follow (Giannone et al. 2010).

${ }^{9}$ Data sources are given in the Appendix A.
} 
(2013) report an average divergence in bilateral real GDP growth rates of about 1.75 percent for 20 rich economies in the three decades before the 2008 downturn. ${ }^{10}$ By this measure, the state economies within the United States are more asynchronous than comparable international economies. ${ }^{11}$ That is, Figure 1 shows us that the current ability of the United States to cohere as a monetary union cannot be attributed to synchronized business cycles among the states.

We can correspondingly measure the synchronicity between the output of the states whose residents consistently vote Democratic (Blue) in presidential elections and the output of states whose residents consistently vote Republican (Red) in presidential elections. Here, we designate a state as Blue if a majority of its voters chose a Democratic presidential candidate in every election between 1989 and 2015; and we designate it as Red if the majority of its voters chose a Republican presidential candidate in every election during the period. ${ }^{12}$ We note that a political designation does not represent an underlying political characteristic that is orthogonal to economic conditions. This is appropriate for our purposes: We are interested in whether the groups of states-as different as they are in terms of things like income, urbanization, physical geography, and education-are nevertheless either synchronized (this section) or able to share risk (next sections).

Using these designations, the measure of synchronicity between Blue states and Red states is:

$$
\psi_{\text {blue }, \text { red }, t}=-\left|\left(\ln Y_{\text {blue }, t}-\ln Y_{\text {blue }, t-1}\right)-\left(\ln Y_{\text {red }, t}-\ln Y_{\text {red }, t-1}\right)\right|,
$$

where $Y_{\text {blue }, t}$ is t-period output of Blue states, and $Y_{\text {red }, t}$ is the t-period output of Red states. This cross-color synchronicity is shown by the dashed line in Fig. $1 .{ }^{13}$ Until the mid-2000s, the economic activity in two groups of states were about as synchronised with each other as were the states within the country as a whole. However, the two diverged somewhat more markedly from each other in the run up to the crisis of 2008, and they only briefly returned to the degree of synchronicity exhibited by the country as a whole before diverging yet again. ${ }^{14}$ A Chow test for a structural break half-way through the sample (significant at the one-percent level) reinforces the visual impression that economic growth in the Blue and Red states is more asynchronous now than in the past.

Other differences between the Blue states and the Red states become apparent when we examine the synchronicity within each of the two groups. Letting $b$

\footnotetext{
${ }^{10}$ Developing economies are less synchronised; see Calderón et al. (2007).

${ }^{11}$ This conclusion also holds for an alternative measure (not reported) of synchronicity that controls for common shocks. The alternative measure equals the negative of the average absolute difference between residuals from regressions of state growth rates on state and year fixed effects.

${ }^{12}$ We designate all other states as Swing states, which we discuss in subsequent sections. Using these designations, Blue states include: CA, CT, DE, HI, IL, MA, MD, ME, MI, MN, NJ, NY, OR, PA, RI, VT, WA, and WI; Red states include: AK, AL, ID, KS, MS, ND, NE, OK, SC, SD, TX, UT, WY; and Swing states include: AR, AZ, CO, FL, GA, IN, IO, KY, LA, MO, MT, NC, NH, NM, NV, OH, TN, VA, WV.

${ }^{13}$ Appendix B provides a corresponding figure depicting the synchronicity between low-income and highincome states, and the synchronicity between rural and urban states. As shown in the appendix, both pairs are out of sync (as out of sync the U.S. as a whole), but neither pair is as out of sync as are the Blue and Red states.

${ }^{14} \mathrm{~A}$ similar pattern arises using the alternative measure of synchronicity that controls for common shocks.
} 
equal the number of Blue states, and $r$ equal the number of Red states, the average synchronicity within each color group is given by:

$$
\begin{aligned}
& \psi_{\text {Blue }, t}=\frac{-1}{b(b-1)} \sum_{i}^{b} \sum_{j}^{b}\left|\left(\ln Y_{i, t}-\ln Y_{i, t-1}\right)-\left(\ln Y_{j, t}-\ln Y_{j, t-1}\right)\right|, \forall i, j \in \text { Blue } \\
& \psi_{\text {Red }, t}=\frac{-1}{r(r-1)} \sum_{i}^{r} \sum_{j}^{r}\left|\left(\ln Y_{i, t}-\ln Y_{i, t-1}\right)-\left(\ln Y_{j, t}-\ln Y_{j, t-1}\right)\right|, \forall i, j \in \text { Red }
\end{aligned}
$$

These measures are shown in Fig. 2: the solid line gives the synchronicity among Blue states, and the dashed line gives the synchronicity among the Red states. The economies of the Blue states move together more than do the economies of the Red states. The difference between the two color groups is most evident recently: change in economic activity among Blue states has converged, while it has diverged among Red states. Over the period as a whole, the average asynchronicity in bilateral GDP growth rates among the consistently Blue states is about 1.9 percent; and the average asynchronicity among the consistently Red states, at about 3.3 percent, is much more pronounced. $^{15}$

Overall, the synchronicity measures given in this section indicate that-in terms of economic activity-the state economies of the United States diverge greatly. For the country as a whole, the economies of the individual states are as varied as if they were distinct countries. This is particularly true of the Red states. Moreover, for Red states, the asynchronicity has been greatest over the last decade. Whether within the color groups, across the color groups, or for the country as a whole, economic activity across the states varies greatly. In the next section, we explore whether the pronounced asynchronicity in economic activity is carried over to consumption, or if instead consumption risk is shared across the states.

\section{Consumption Smoothing}

The asynchronicity of economic activity across states, regions, and countries in principle provides an opportunity for integrated areas to share risk in order to smooth their consumption. ${ }^{16}$ That is, consumers in integrated economies can benefit from output asynchronicity. In the simplest case of two economies with exogenously given production, individuals in each of the two economies can share risk by holding assets that pay out in the other economy's production. Their consumption would then be related even when their production is not. ${ }^{17}$ With consumption risk spread between

\footnotetext{
${ }^{15}$ The difference, 1.4 percentage points with a standard error is 0.2 percent, is statistically significant at all standard confidence levels.

${ }^{16}$ There is a large literature exploring the many facets of the theoretical relationship between economic integration and GDP synchronicity. Doyle and Faust (2005) provide an overview in the context of related empirical work.

${ }^{17}$ For example, with iso-elastic utility and complete asset markets, the consumption growth rates in the two economies would be completely equalised.
} 


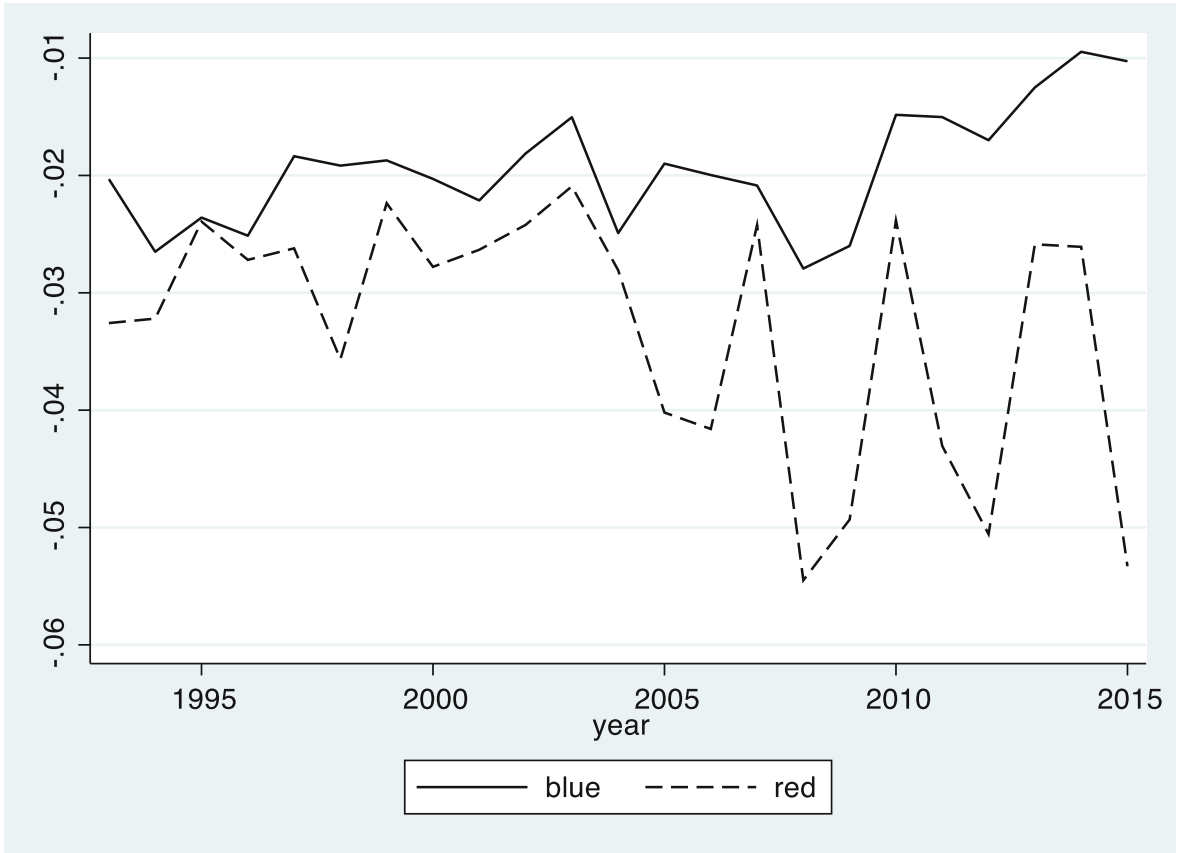

Fig. 2 Average GDP synchronicity within each color group. Note: As illustrated here, greater synchronicity, $\psi_{i, j, t}$, again is indicated by a higher numerical value (a smaller magnitude) of the average value of $\psi_{i, j, t}=-\left|\left(\ln Y_{i, t}-\ln Y_{i, t-1}\right)-\left(\ln Y_{j, t}-\ln Y_{j, t-1}\right)\right|$, where $i$ and $j$ are defined within the relevant groupings

the two economies, neither economy's consumption would be tied lock step to its own production, and divergent economic activity would allow both economies to smooth consumption. Moreover, in the spirit of Helpman and Razin (1978), Obstfeld (1994) shows that integration itself can induce specialization, which in turn would lead to output asynchronicity. ${ }^{18}$

In this section, we look at consumption and income together to assess the extent of state-level consumption smoothing within the United States. Using consumption data not available at the time of the previous studies of U.S. consumption smoothing, we find that a great deal of consumption risk indeed is shared within the United States. This contrasts with the international evidence. That is, while economic activity is as asynchronous across the states as it is internationally, consumption smoothing tells a different story: consumption risk is shared within the United States, even across the Blue and Red states, much more than it is internationally. (How that sharing is accomplished is the subject of Section 4.)

This section's examination of consumption and income follows (Rangvid et al. 2016), Kose et al. (2009), Lewis (1996), Obstfeld (1993), and others who examine the

\footnotetext{
${ }^{18}$ Kalemli-Ozcan et al. (2003) and Imbs (2004) document empirically that specialization and risk sharing are linked both regionally and internationally; Basile and Girardi (2010), in turn, corroborate this finding in a careful examination of regional risk sharing and specialization within the EU 15 member states, and they themselves invite studies of the risk sharing channels.
} 
diversification of consumption risk internationally. Specifically, we regress idiosyncratic consumption growth on idiosyncratic income growth. Where consumption risk is shared, the estimated coefficient on idiosyncratic income should be low.

To measure consumption for each state, we use the Regional Economic Accounts of the Bureau of Economic Analysis' new data on personal consumption expenditures, which is now the Bureau's most comprehensive measure of household consumption. The Bureau of Economic Analysis released its first prototype of these data in 2014, but the series begins in 1997; this makes it possible to include a substantial period both before and after the global crisis. Earlier key studies relied on retail sales data to gauge consumption. While the retail sales data go further back in time, the new personal consumption expenditures data provide a more comprehensive measure of the purchases by residents of each state (including such things as travel expenditures, housing and financial services, and the net expenditures of nonprofit institutions serving households). Furthermore, it does not conflate those purchases with purchases made by nonresidents. These new data also allow us to separately examine the use of durable goods purchases as a mechanism for smoothing consumption. For comparability with earlier work, we focus on total personal consumption in this section; however, in the next section, where we study the various channels of smoothing, we separate out durable goods purchases, which themselves can be thought of as a saving vehicle that can be used to smooth consumption.

We begin by examining consumption risk sharing within the United States as a whole. Let $c_{i, t}$ equal the growth rate of consumption in the $i^{t h}$ state in year $t$. We regress each state's idiosyncratic rate of consumption growth on its idiosyncratic rate of GDP growth in a panel, as follows:

$$
c_{i, t}-\bar{c}_{t}=\beta_{u . s .}\left(y_{i, t}-\bar{y}_{t}\right)+v_{i, t} .
$$

In each period, the average consumption, $\bar{c}_{t}$, and the average output growth, $\bar{y}_{t}$, is each defined over all of the United States.

The first column of Table 1 gives the results of this regression. As shown, the estimated coefficient on idiosyncratic output growth is 0.22 . That is, just over onefifth of a state's idiosyncratic output growth shows up in a corresponding change in its consumption. This implies a much higher degree of risk sharing than is reported in international studies. For example, with more than a century of data for risk sharing among rich countries, Rangvid et al. (2016) report values of consumption risk sharing that imply coefficient estimates ranging from about 0.40 to about 0.85 . $^{19}$ The much lower coefficient estimate we find for the United States is well below even the nadir of their international values. For the country as a whole, consumption risk sharing among the states is much greater than is international consumption risk sharing.

\footnotetext{
${ }^{19}$ Rangvid et al. (2016) construct 'consumption risk sharing values' by multiplying their regression estimates by 100 , then subtracting the product from 100 . They report consumption risk sharing values of 15 to 60 , which imply the coefficient estimates of about 0.40 to 0.85 mentioned above. In terms of their measures, our estimate of about 0.22 implies a consumption risk sharing value of 78 , which exceeds even the peak of their reported international risk sharing. Risk sharing among emerging and low-income economies tends to be even lower.
} 
Table 1 Consumption smoothing

\begin{tabular}{lll}
\hline$c_{i, t}-\bar{c}_{t}$ & $(1)$ & $(2)$ \\
\hline$y_{i, t}-\bar{y}_{t}$ & 0.2234 & \\
& $(0.012)$ & \\
$d_{\text {blue }, i}\left(y_{i, t}-\bar{y}_{t}\right)$ & & 0.2131 \\
& & $(0.060)$ \\
$d_{\text {red }, i}\left(y_{i, t}-\bar{y}_{t}\right)$ & & 0.2307 \\
& & $0.048)$ \\
$d_{\text {swing }, i}\left(y_{i, t}-\bar{y}_{t}\right)$ & & 0.2413 \\
& 900 & $(0.074)$ \\
Observations & 0.299 & 900 \\
$R^{2}$ & & 0.301 \\
\hline
\end{tabular}

This table provides estimates of Eqs. 3.1 and 3.2 using annual data from 1997 through 2015; robust standard errors are clustered at the state level and reported in parentheses

We also measure the extent of consumption risk sharing for the states defined above as Red, Blue, and Swing. ${ }^{20}$ Specifically, we estimate the following regression using the same panel data:

$$
c_{i, t}-\bar{c}_{t}=\sum_{\substack{j=b l u e, \\ \text { red, } \\ \text { swing }}} \beta_{j} d_{j, i}\left(y_{i, t}-\bar{y}_{t}\right)+u_{i, t},
$$

where $d_{j, i}$ are indicator variables for states whose residents have voted consistently Democratic $(j=$ blue $)$ or consistently Republican $(j=r e d)$ in presidential elections, or whose residents have not voted consistently for one party or the other $(j=$ swing $)$. What is measured here is the average risk sharing of each color grouping.

The results of this estimation are shown in the second column of Table 1. While the point estimates themselves might indicate that consumption in the Blue states is slightly less tied to idiosyncratic state GDP growth than is the consumption in Red states or in Swing states, the differences are minor. ${ }^{21}$ The estimates for each of the three state groupings are all roughly on par with the estimate for the country as a whole. All of the coefficient estimates indicate that there is much more consumption risk sharing among the states than across international borders.

The estimates provided in this section show that consumption risk sharing within the United States is substantial. The substantial asynchronicity in economic activity across states enables residents to share income volatility risk and correspondingly

\footnotetext{
${ }^{20}$ Note that here we still subtract the country's consumption and the country's income from each states' consumption and income. Thus, we measure how much the states of each color share with the country as a whole, not how much they share among themselves.

${ }^{21}$ They are small both in absolute terms and relative to their standard errors.
} 
smooth their consumption regardless of political differences. In the next section, we explore how that risk sharing is accomplished.

\section{Risk Sharing Channels}

This section examines the key channels for sharing consumption risk. That is, while the previous section documented that consumption risk is shared within the United States, this section empirically examines the mechanisms through which it is shared. We estimate the extent to which idiosyncratic consumption is smoothed via financial markets and via fiscal transfers, and we expand the usual list of U.S. channels to include changes in population, durable goods consumption, and prices. ${ }^{22}$ Allowing for the additional channels, we are able to observe more risk sharing than has previously been reported for the United States as a whole, and we find important differences between the Blue, Red, and Swing states.

As before, we begin with an examination of the country as a whole, then we look separately at Blue, Red, and Swing states. The political division is likely to be particularly important in examining the fiscal channel: Altig et al. (2019) document the differential effects of the 2017 tax reform on Blue states and Red states; and Levitt and Snyder (1995) show that political parties can alter the geographic distribution of Federal appropriations, while (Kiewiet and McCubbins 1985) show that such appropriations are related to prevailing economic conditions. Additionally, Carlino et al. (2021) show that the downstream, within-state effect of Federal expenditures is influenced by the political party dominating the individual state. We note that where one channel is constricted or expanded, other channels might also be expected to be altered.

Our exploration of the channels for the United States as a whole begins with the now-standard identity of Asdrubali et al. (1996):

$$
Y_{i, t}=\frac{Y_{i, t}}{\tilde{Y}_{i, t}} \frac{\tilde{Y}_{i, t}}{Y_{i, t}^{d}} \frac{Y_{i, t}^{d}}{C_{i, t}} C_{i, t} .
$$

As above, $Y_{i, t}$ is defined as the $i^{\text {th }}$ state's GDP. $\tilde{Y}_{i, t}$ is defined as the $i^{\text {th }}$ state's income, which includes net payments of dividend, interest and rent across state borders. $Y_{i, t}^{d}$ is defined as the $i^{\text {th }}$ state's disposable income, which accounts for taxes and transfers (including social security), and Federal grants to states; and $C_{i, t}$ is the $i^{\text {th }}$ state's consumption.

As pointed out by Asdrubali et al. (1996), risk sharing via the capital market diminishes the correlation between $\tilde{Y}_{i, t}$ and $Y_{i, t}$. Likewise, risk sharing via Federal transfers shows up in the link betwee $\tilde{Y}_{i, t}$ and $Y_{i, t}^{d}$, while the role of credit shows up

\footnotetext{
${ }^{22}$ In related work outside the United States, Jappelli and Pistaferri (2011) use detailed Italian survey data, which now include data on the consumption of durables, to carefully quantify household consumption smoothing in Italy; and Labhard and Sawicki (2006) examine prices as a smoothing mechanism within the United Kingdom using a slightly different approach.
} 
in the link between $Y_{i, t}^{d}$ and $C_{i, t}$. Finally, risk that remains unshared shows up in the correlation that remains between $C_{i, t}$ and $Y_{i, t}$. Thus, their identity provides a way of assessing the empirical importance of these consumption smoothing channels.

To the smoothing channels they originally explored, we incorporate three more channels directly into the framework in a way that maintains the identity. ${ }^{23}$ First, we allow for smoothing through the purchases of consumer durables, which can be thought of as a nonfinancial form of saving. Second, we examine the impact of yearby-year population changes. Asdrubali et al. (1996) used decade-long population changes to explore the possibility of longer-run smoothing via migration. Here, we use annual population data, so we are able to measure the year-by-year effect in concert with the other channels. ${ }^{24}$ Finally, we add a price channel, which, for the United States, is the same as a real exchange rate channel since the "nominal exchange rate" is fixed across all states. To implement the price channel, we construct state price indices from raw price data obtained from the Council for Community and Economic Research, which has published the Cost of Living Index quarterly since $1968 .^{25}$ These additions yield a new identity, one that separates price changes from real variables and includes the population and nondurables channels:

$$
Y_{i, t}=P_{i, t} L_{i, t} \frac{Y_{r, i, t}}{\tilde{Y}_{r, i, t}} \frac{\tilde{Y}_{r, i, t}}{Y_{r, i, t}^{d}} \frac{Y_{r, i, t}^{d}}{C_{r, i, t}} \frac{C_{r, i, t}}{C_{n d, r, i, t}} C_{n d, r, i, t}
$$

Here, $P_{i, t}$ is the $i^{t h}$ state's price level, ${ }^{26}$ and $L_{i, t}$ is its population; the subscripts $r$ indicate real per capita values; $C_{D, r, i, t}$ represents real per capita durable goods consumption; and $C_{n d, r, i, t}$ represents real per capita consumption of nondurable goods and services, which is the difference between real total consumption and real durable goods consumption: $C_{n d, r, i, t}=C_{r, i, t}-C_{D, r, i, t}$. Taking logs and first differences, this becomes:

$$
y_{i, t}=p_{i, t}+l_{i, t}+\left(y_{r, i, t}-\tilde{y}_{r, i, t}\right)+\left(\tilde{y}_{r, i, t}-y_{r, i, t}^{d}\right)+\left(y_{r, i, t}^{d}-c_{r, i, t}\right)+\left(c_{r, i, t}-c_{n d, r, i, t}\right)+c_{n d, r, i, t},
$$

where $p_{i, t}$ and $l_{i, t}$ are the log changes in state prices and population, and $y_{r, i, t}, \tilde{y}_{r, i, t}$, $y_{r, i, t}^{d}, c_{r, i, t}, c_{n d, r, i, t}$ are the log changes in state per capita GDP, income, disposable income, consumption, and nondurable consumption.

\footnotetext{
${ }^{23}$ Work by Chinn and Wei (2013) and others suggests that one might also wish to examine smoothing via what would be state 'current accounts.' We do not add the current account as a channel here for two reasons: first, only limited state-level data are available; and, second, in the absence of state-level official reserve transactions, state-level current accounts are in principle mirrored in the capital transactions captured by the channels described above.

${ }^{24}$ Our use of population captures the extent to which idiosyncratic population changes account for consumption smoothing at the annual level; but, as in earlier work, the measure embeds, not just migration, but also net births less deaths.

${ }^{25}$ The data underlying the Cost of Living Index have been used by Parsley and Wei (1996) to study law of one price convergence and by Nakamura and Steinsson (2013) to study fiscal multipliers.

${ }^{26}$ Here, $P_{i, t}$ deflates state GDPs; however, the data come from consumer prices; this introduces a measurement error, and we discuss its implications when we present the empirical results below.
} 
To gauge the relative role of each potential smoothing channel under consideration, one can multiply Eq. 4.3 by $y_{i, t}$ and take the expected value; when scaled by the variance of $y_{i, t}$, this gives a simple sum:

$$
1=\beta_{P}+\beta_{L}+\beta_{K}+\beta_{F}+\beta_{S}+\beta_{C_{d}}+\beta_{U},
$$

where each term is equivalent to a single coefficient in a univariate regression. ${ }^{27}$ Imposing the adding up constraint of Eq. 4.4 implies the following panel regression:

$$
\begin{aligned}
p_{i, t} & =v_{P, t}+\beta_{P} y_{i, t}+\eta_{P, i, t} \\
l_{i, t} & =v_{L, t}+\beta_{L} y_{i, t}+\eta_{L, i, t} \\
y_{r, i, t}-\tilde{y}_{r, i, t} & =v_{K, t}+\beta_{K} y_{i, t}+\eta_{K, i, t} \\
\tilde{y}_{r, i, t}-y_{r, i, t}^{d} & =v_{F, t}+\beta_{F} y_{i, t}+\eta_{F, i, t} \\
y_{r, i, t}^{d}-c_{r, i, t} & =v_{S, t}+\beta_{S} y_{i, t}+\eta_{S, i, t} \\
c_{r, i, t}-c_{n d, c, i, t} & =v_{D, t}+\beta_{D} y_{i, t}+\eta_{D, i, t} \\
c_{n d, c, i, t} & =v_{U, t}+\beta_{U} y_{i, t}+\eta_{U, i, t} .
\end{aligned}
$$

Here $v_{\cdot, t}$ are time fixed effects that capture factors that are common across states in each period, making the estimates analogous to the idiosyncratic measures used in Sections 2 and 4 . We write this more compactly as:

$$
\mathbf{y}_{i, t}=\boldsymbol{v}_{t}+\boldsymbol{\beta} y_{i, t}+\boldsymbol{\eta}_{i, t},
$$

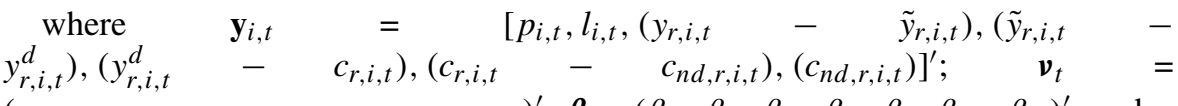
$\left(v_{P, t}, v_{L, t}, v_{K, t}, v_{F, t}, v_{S, t}, v_{C_{d}, t}, v_{U, t}\right)^{\prime} ; \boldsymbol{\beta}=\left(\beta_{P}, \beta_{L}, \beta_{K}, \beta_{F}, \beta_{S}, \beta_{C_{d}}, \beta_{U}\right)^{\prime}$, and $\boldsymbol{\eta}$ $=\left(\eta_{P, i, t}, \eta_{L, i, t}, \eta_{K, i, t}, \eta_{F, i, t}, \eta_{S, i, t}, \eta_{C_{D}, i, t}, \eta_{C_{n} d, i, t}\right)^{\prime}$.

The panel estimates of Eq. 4.6 measure the role of each smoothing channel and are given in Table 2.

\subsection{All States}

The first column of Table 2 gives the channel estimates for a panel that includes all states. Consistent with earlier studies, the largest share of smoothing occurs in the capital market, given in the first pair of rows. Capital markets now smooth about 43 percent of states' idiosyncratic risk. Despite the many changes in capital markets in the United States in the last three decades, this U.S.-wide estimate is roughly on par with that of Asdrubali et al. (1996), who find that about 39 percent of states' idiosyncratic risk is shared in U.S. capital markets as a whole. ${ }^{28}$

\footnotetext{
${ }^{27}$ Specifically, $\beta_{P}=\frac{\operatorname{cov}\left(p_{i, t}, y_{i, t}\right)}{\operatorname{var}\left(y_{i, t}\right)}, \beta_{L}=\frac{\operatorname{cov}\left(l_{i, t}, y_{i, t}\right)}{\operatorname{var}\left(y_{i, t}\right)}, \beta_{K}=\frac{\operatorname{cov}\left(y_{r, i, t}-\tilde{y}_{r, i, t}, y_{i, t}\right)}{\operatorname{var}\left(y_{i, t}\right)}, \beta_{F}=\frac{\operatorname{cov}\left(\tilde{y}_{r, i, t}-y_{r, i, t}^{d}, y_{i, t}\right)}{\operatorname{var}\left(y_{i, t}\right)}$, $\beta_{S}=\frac{\operatorname{cov}\left(y_{r, i, t}^{d}-c_{r, i, t}, y_{i, t}\right)}{\operatorname{var}\left(y_{i, t}\right)}, \beta_{C_{d}}=\frac{\operatorname{cov}\left(c_{r, i, t}-c_{n d, c, i, t}, y_{i, t}\right)}{\operatorname{var}\left(y_{i, t}\right)}, \beta_{C_{n} d}=\frac{\operatorname{cov}\left(c_{n d, c, i, t}, y_{i, t}\right)}{\operatorname{var}\left(y_{i, t}\right)}$.

${ }^{28}$ (Hepp and von Hagen 2013) find a slightly higher fraction, about 50 percent, for Germany since the nineties, but (Buti 2007) reports lower numbers for most of the Euro Area.
} 
Table 2 Channels of consumption smoothing

\begin{tabular}{lllll}
\hline & $\begin{array}{l}\text { U.S. } \\
(1)\end{array}$ & $\begin{array}{l}\text { Blue } \\
(2)\end{array}$ & $\begin{array}{l}\text { Red } \\
(3)\end{array}$ & $\begin{array}{l}\text { Swing } \\
(4)\end{array}$ \\
\hline Capital: $\beta_{K}, \delta_{j} \beta_{K}$ & 0.4288 & 0.4489 & 0.3764 & 0.4980 \\
& $(0.0236)$ & $(0.0517)$ & $(0.0424)$ & $(0.0460)$ \\
Fiscal: $\beta_{F}, \delta_{j} \beta_{F}$ & 0.1579 & 0.1703 & 0.2627 & 0.0604 \\
& $(0.0320)$ & $(0.0710)$ & $(0.0600)$ & $(0.0548)$ \\
Saving: $\beta_{S}, \delta_{j} \beta_{S}$ & 0.1699 & 0.1333 & 0.1329 & 0.1569 \\
Durables: $\beta_{C_{d}}, \delta_{j} \beta_{C_{d}}$ & $(0.0179)$ & $(0.0400)$ & $(0.0329)$ & $(0.0330)$ \\
Prices: $\beta_{P}, \delta_{j} \beta_{P}$ & 0.0207 & 0.0392 & 0.0115 & 0.0339 \\
Population: $\beta_{L}, \delta_{j} \beta_{L}$ & $(0.0032)$ & $(0.0073)$ & $(0.0047)$ & $(0.0062)$ \\
Unshared: $\beta_{U}, \delta_{j} \beta_{U}$ & 0.0293 & 0.0583 & 0.0250 & 0.0178 \\
Observations & $(0.0139)$ & $(0.0401)$ & $(0.0131)$ & $(0.0164)$ \\
\hline
\end{tabular}

This table provides estimates of Eqs. 4.6 and 4.7 using annual data from 1997 through 2015; robust standard errors are clustered at the state level and reported in parentheses

The next pair of rows gives the estimate for the extent of smoothing that occurs through taxes and transfers. ${ }^{29}$ About 16 percent of idiosyncratic output is smoothed through such fiscal flows. ${ }^{30}$ Again-despite the political changes in the intervening period-this estimate (for the United States as a whole) is close to that of Asdrubali et al. (1996), who find that about 13 percent of states' idiosyncratic risk is shared this way. ${ }^{31}$ It is also not far from the range of estimates provided in von Hagen (1998), who gives a summary of earlier studies, though it is somewhat lower than the more recent estimate of roughly 25 percent reported in Feyrer and Sacerdote (2013). Notably, the role of U.S.-wide fiscal flows remains higher than the four to six percent reported in Buti (2007) for European countries by the European Commission just prior to the Financial Crisis. ${ }^{32}$ (However, as we discuss below, the role played by U.S. fiscal flows is not uniform: it is much smaller for some groups of states.)

\footnotetext{
${ }^{29}$ While the introduction emphasizes the relevance of risk sharing for the viability of monetary unions, the usefulness of fiscal flows as a channel for sharing states' idiosyncratic risks is also relevant for the legal literature on redistributive taxation. See, for example, Brooks (2014).

${ }^{30}$ Since we are interested in the ability of states to share risks across state lines, we follow the literature and report how much fiscal flows offset states' idiosyncratic risks. Fiscal flows typically offset somewhat more of the nation-wide, overall fluctuations in GDP.

${ }^{31}$ We cannot reject at any reasonable confidence level the hypothesis that the fiscal flow channel amounts to the 13 percent given in Asdrubali et al. (1996).

${ }^{32}$ It is also higher than the roughly ten percent reported for inter-provincial fiscal smoothing within China; see Du et al. (2011).
} 
The role of credit or saving, as conventionally measured, is given in the next pair of rows. For the country as a whole, credit smooths an estimated 17 percent of states' idiosyncratic risk. This estimate is remarkably close to European estimates of about 15 percent, reported by the European Commission in Buti (2007). It is also somewhat higher than the U.S. estimate of 12 percent reported in Milano and Reichlin (2017) and Milano (2017), which is much lower than the 23 percent originally reported by Asdrubali et al. (1996).

The next three pairs of rows provide estimates for the added channels: durable goods, prices, and labor. Because of the newly available state-by-state consumption data, we are able to estimate the extent to which durable goods purchases are used as a saving device to further smooth consumption. For the United States as a whole, durable goods smooth about two percent of states' idiosyncratic risk. While this is small compared with estimates for the traditional credit channel, it is very tightly estimated, and combined with the conventional credit measure it brings the estimate of the role of savings up to 19 percent.

The role of changes in states' prices is given in the next pair of rows. While the states share a single currency (so there is no scope for smoothing through nominal exchange rates), their prices nevertheless adjust enough relative to one another to have some risk sharing impact. Specifically, the estimate indicates that changes in relative prices smooth about three percent (statistically significant at the five percent level) of states' idiosyncratic risk. Note that the available state-level price data include only consumer prices, rather than a wider set of prices, and the use of the narrow set of prices to deflate states' GDPs introduces a measurement error that biases downward the value of our estimate. Hence, the estimates given in Table 2 might more appropriately be considered lower bounds on the fraction smoothed by prices. That said, we observe that our estimate is in keeping with that found across regions within the United Kingdom by Labhard and Sawicki (2006), who use a slightly different, though related, approach.

Substantially more consumption smoothing occurs through migration and other changes in population. As shown in the next pair of rows, migration and other changes in population smooth almost eight percent of states' idiosyncratic income growth. One might have expected an even larger value since the United States is often regarded as having a highly mobile labor force that is very responsive to labor conditions; and intra-U.S. migration remains high relative to intra-Europe migration. ${ }^{33}$ However, Dao et al. (2017) show that the U.S. migration response to relative economic conditions-while still high by international standards-has roughly halved since the 1990s, the start of the sample period in our study. ${ }^{34}$

Together, the three additional channels-durable goods purchases, changes in relative prices, and changes in population-reduce the unshared idiosyncratic risk by more than half. They account for roughly 13 percent more consumption smoothing, which leaves states with less than 12 percent of their idiosyncratic risk unshared.

\footnotetext{
${ }^{33}$ These findings are related to those of Dao et al. (2017), to House et al. (2019), and to (Furceri et al. 2020) who compare U.S. and European labor sensitivity to economic conditions.

${ }^{34}$ Likewise, Furceri et al. (2020) also note that the U.S. role of migration has fallen.
} 


\subsection{Blue and Red}

Next, we examine the channels within each color grouping. That is, we adapt (4.6) to estimate it for states whose residents vote consistently Democratic, for states whose residents vote consistently Republican, and for the remaining states. Rewriting (4.6) using the same indicators of color used in Section $3, d_{j, i}$, where $j=$ red, blue, and swing, we have:

$$
\mathbf{y}_{i, t}=\sum_{\begin{array}{c}
j=\text { blue, } \\
\text { red, } \\
\text { swing }
\end{array}} \boldsymbol{v}_{j, t}+\sum_{\begin{array}{c}
j=\text { blue } \\
\text { red, } \\
\text { swing }
\end{array}} \boldsymbol{\beta}_{j} d_{j, i} y_{i, t}+\boldsymbol{\eta}_{i, t} .
$$

The results are shown in columns 2 through 4 of Table 2.

For the Blue states, shown in column 2, the standard channels-capital markets, fiscal flows, and saving-show only minor changes. However, smoothing through durables is notably higher. While still relatively small, the use of durable goods as a saving device to smooth consumption-at almost four percent-is tightly estimated and roughly double the estimate for the country as a whole. ${ }^{35}$ The point estimates for the roles of prices, and population changes are also substantially higher than for the country as a whole; however the estimates are noisy, so we cannot reliably conclude that prices and population changes are more responsive to economic conditions in Blue states than in the country as a whole.

The estimates for the Red states are given in column 3. Here, the differences are somewhat more marked. In comparison with estimates from the country as a whole, Red states appear to benefit much more from fiscal flows, though the standard errors are too high state conclusively that the benefit is greater. ${ }^{36}$ Importantly, despite smoothing through fiscal flows, Red states seem nevertheless to be left with substantially more residual risk. Specifically, as shown in the second pair of rows, fiscal flows appear to insulate more than a quarter of the idiosyncratic risk faced by Red states. This compares with a point estimate of only 16 percent for the country as a whole. As shown in the last rows of estimates, Red states are left with unshared idiosyncratic risk of about 15 percent, which (statistically significant at the ten percent level) is greater than that faced by the country as a whole. ${ }^{37}$

Comparing Red states directly with Blue states, we find three large and statistically significant differences. First, the use of durable goods as a saving device to smooth consumption in Red states is about a quarter what it is in Blue states. Second, the role of migration and other population changes in Red states is about one-third of what it is in Blue states. Third, residual, unshared risk is higher for the Red states.

\footnotetext{
${ }^{35}$ The difference is statistically significant at standard confidence levels.

${ }^{36}$ Remarkably, we find (in separate estimates reported in Appendix B) that, unlike Red states as a group, low-income states and rural states smooth very little-or none at all-of their consumption through fiscal flows.

${ }^{37}$ As reported in Appendix B, differences in unshared risk are much less pronounced both between lowincome and high-income states, and between rural and urban states.
} 
In addition, we find that-of all of the channels of smoothing-only the fiscal flows channel appears to be larger in Red states than Blue states.

The estimates for the Swing states, those that do not consistently vote Blue or Red, are given in column 4. Like the Red states, the biggest difference occurs in the fiscal flows. Perhaps surprisingly-and in contrast to both Blue and Red statesSwing states benefit very little-if at all-from risk sharing through fiscal flows. The point estimate of six percent is roughly on par with the EU estimates, and it has a standard error of five percent, which (at any conventional significance levels) renders it indistinguishable from zero.

If one viewed U.S. Swing states as 'up for grabs,' one might have expected Federal expenditures to be aggressively used to mitigate their economic vicissitudes. That is, one might have expected the role of fiscal flows to be high, not indistinguishable from zero. However, it is possible that the potential for fiscal smoothing in Swing states may be inhibited by their weak Congressional influence. Cohen et al. (2011) document that Congressional committee chairs consistently direct federal funds flowing through their committees to their own states. Consistent with Congressional influence argument, we find that Swing states indeed held relatively few chairs on important committees in the U.S. House and Senate during our sample period. ${ }^{38}$

The Swing states largely accomplish their smoothing through factor markets. Overwhelmingly the largest portion of their smoothing, almost 50 percent, occurs through capital markets, while another 16 percent occurs through credit markets; and another 15 percent occurs through migration and other population changes. The role of migration and other population changes in smoothing the idiosyncratic risk of swing states is considerably larger than it is in either Blue or Red states; finally, while durables remain only a minor channel for smoothing, Swing states do smooth more than average using durables. ${ }^{39}$

Overall, the differences in the channels of smoothing used by the three groups are notable. In terms of fiscal smoothing, Blue states might be thought of as being comparable to Canada, while Red states might be thought of as comparable to countries where internal fiscal flows are more important in this regard, such as within the United Kingdom or within Germany. ${ }^{40}$ Swing states, in contrast, do not appear to systematically benefit from fiscal smoothing at all. Additionally, despite the extent of their fiscal smoothing, Red states are left with substantial unshared idiosyncratic risk. In contrast, Blue states use a breadth of channels to smooth virtually all of their idiosyncratic consumption risk, and Swing states smooth a great deal of their risk through factor mobility.

\footnotetext{
${ }^{38}$ We combine the data of Stewart and Woon (2017) with the influential committee designations of Stewart (2012) to calculate the number of key Congressional committee chairs held by states in each color grouping: Over the sample period, Blue states held an average of 3.2 important chairs and Red states held 3.6, while Swing states held only 2.3 important chairs. Key Congressional committee chairs are traditionally awarded based on seniority, so the lower number of Swing state chairs may reflect higher Swing state turnover.

${ }^{39}$ The population and durables differences are statistically significant at one percent.

${ }^{40}$ See the summary of international work provided by von Hagen (1998).
} 


\section{Conclusion}

This paper takes a fresh look at the United States as a benchmark for risk sharing. Along with newly available data and important changes in capital and labor markets, the passage of time has brought profound changes in political circumstances. Here, we examine GDP synchronicity and the scope and the channels for sharing idiosyncratic consumption risk across the politically divided areas of the United States.

We find that recent U.S. political divisions are mirrored in macroeconomic divisions, but that the country nevertheless continues to smooth consumption risk across the political divide. Specifically, the economies of the politically divided areas are more asynchronous than is typical of even separate countries, but the areas share consumption risk more than separate countries do. We also find that their risk-sharing channels differ markedly: their reliance on fiscal smoothing and on population changes differs, as does the extent of their remaining, unshared idiosyncratic risk. Notably, Red states benefit the most from fiscal smoothing, yet they also end up with the most residual risk; while Swing states rely the most on population changes and benefit little, if at all, from fiscal smoothing; and Blue states have the least remaining risk.

The United States has stood out in the past as an exemplar of mobility of many types within its borders. Now, it stands among the notable exemplars of political division. Our findings show that such political divisions are attended by macroeconomic differences, but the divisions do not prevent states from risk sharing. The evidence suggests that, by themselves, political and economic differences do not necessarily prevent substantial risk sharing within a monetary union.

\section{Appendix A: Data Sources}

Much of the data used in this study comes from the Regional Economic Accounts of the Bureau of Economic Analysis (BEA), and is available online at https://www. bea.gov/regional, with methods described at https://www.bea.gov/regional/methods. cfm. The BEA provides: state GDP, state personal income, and state population. We use annual data from 1993-2015 in Section 2, and since the BEA's introduction of state-level personal consumption expenditures data begins in 1997, we use 1997-2015 for the analysis of consumption smoothing in Sections 3 and 4. An informative description of personal consumption expenditure data and methodology is provided by Awuku-Budu et al. (2013). For state level prices, we construct state-level consumer inflation using individual goods and services price data provided by the Council for Community and Economic Research, and using the fixed-weight methodology of the Bureau of Labor Statistics. Additional details are described in Parsley and Wei (2016). The 'Urban Percentage of the Population for States' comes originally from the Decennial Census of the U.S. Census Bureauconveniently summarized by the Iowa Community Indicators Program, https://www. icip.iastate.edu/tables/population/urban-pct-states-and described in more detail by the Census Bureau: https://www.census.gov/programs-surveys/geography/guidance/ geo-areas/urban-rural/2010-urban-rural.html. Finally, election results were compiled 
from data provided by the office of the Federal Register, https://www.archives.gov/ federal-register/electoral-college/map/historic.html.

\section{Appendix B: Income and Rural/Urban Groupings}

This appendix examines synchronicity and risk-sharing channels using two alternative state groupings. The first grouping is constructed using income designations, and the second grouping is constructed using rural and urban designations. For rough comparability with the political divisions, we designate as 'low-income' those states that remain in the lowest income quartile in all of the sample's election years; and we designate as 'rural' those states that remain in the lowest quartile of the U.S. Census Bureau's urban measure in all of the sample's census years. We correspondingly designate as 'high-income' and as 'urban' those states in the respective upper quartiles in the same years; and we designate the remaining states in each of the two groupings as 'other'. The group of consistently low-income states is made up of: AL, AR, ID, ME, MS, MT, OK, and WV; and high-income states include: AK, CA, CT, DE, MA, NJ, NY, and WY. The group of rural states is made up of: AR, KY, ME, MS, MT, NH, ND, SD, VT, and WV; and the urban states include: AZ, CA, FL, HI, IL, MA, NE, NJ, NY, RI, and UT.

Figure 3 illustrates the pattern of synchronicity between low-income and highincome states, and between rural and urban states, and Table 3 provides estimates of

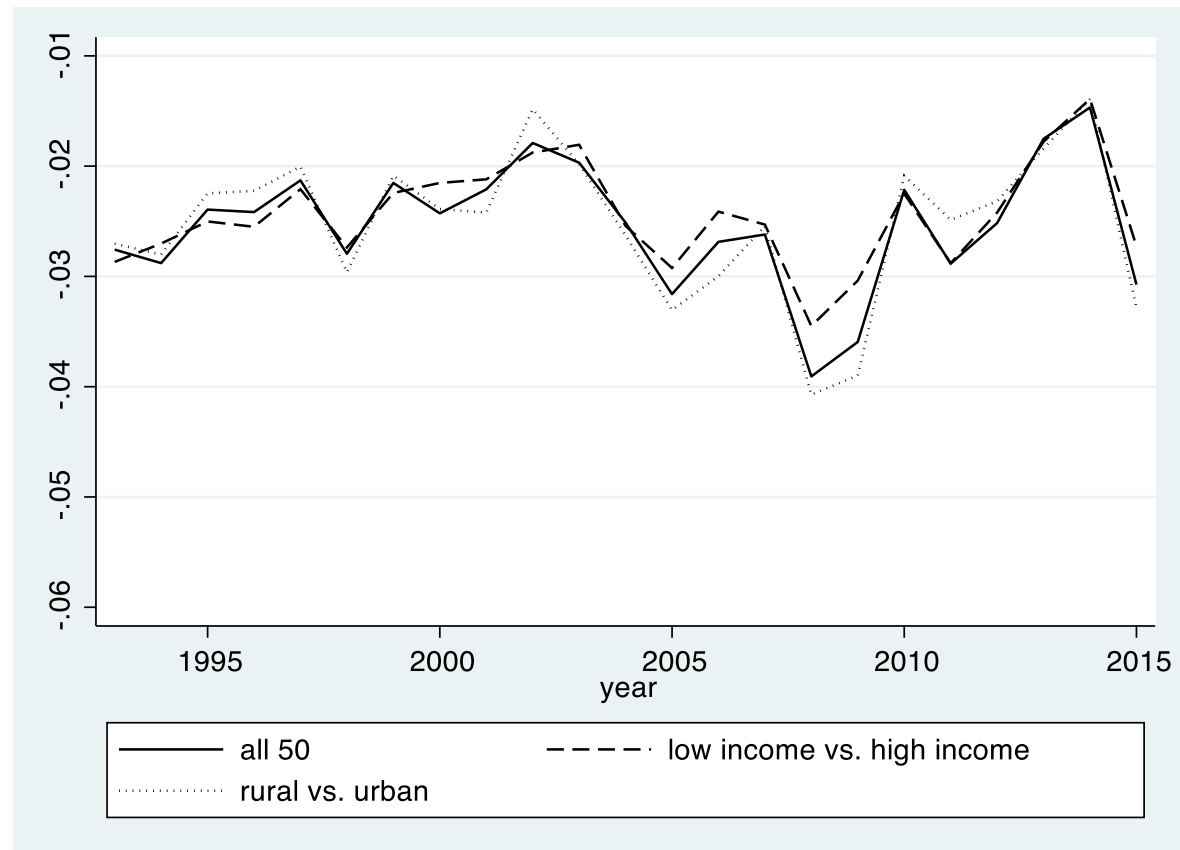

Fig. 3 State GDP synchronicity: alternative state groupings. Note: As illustrated here, greater synchronicity, $\psi_{i, j, t}$, is indicated by a higher numerical value (a smaller magnitude) of the average value of $\psi_{i, j, t}=-\left|\left(\ln Y_{i, t}-\ln Y_{i, t-1}\right)-\left(\ln Y_{j, t}-\ln Y_{j, t-1}\right)\right|$, where $i$ and $j$ are defined within the relevant groupings 
Table 3 Smoothing Channels: Income and Rural/Urban Groupings

\begin{tabular}{llllllll}
\hline & U.S. & $\begin{array}{l}\text { Low } \\
\text { Income } \\
(2)\end{array}$ & $\begin{array}{l}\text { High } \\
\text { Income } \\
(3)\end{array}$ & $\begin{array}{l}\text { Other } \\
\text { Income } \\
(4)\end{array}$ & $\begin{array}{l}\text { Rural } \\
(5)\end{array}$ & $\begin{array}{l}\text { Urban } \\
(6)\end{array}$ & $\begin{array}{l}\text { Other } \\
\text { Rural } \\
(7)\end{array}$ \\
\hline Capital & 0.4288 & 0.5922 & 0.3772 & 0.4483 & 0.4400 & 0.1986 & 0.4859 \\
$\beta_{K}, \delta_{j} \beta_{K}$ & $(0.0236)$ & $(0.0548)$ & $(0.0594)$ & $(0.0293)$ & $(0.0448)$ & $(0.0505)$ & $(0.0323)$ \\
Fiscal & 0.1579 & -0.0644 & 0.3284 & 0.0597 & 0.0424 & 0.2055 & 0.1744 \\
$\beta_{F}, \delta_{j} \beta_{F}$ & $(0.0320)$ & $(0.0762)$ & $(0.0795)$ & $(0.0398)$ & $(0.0660)$ & $(0.0710)$ & $(0.0438)$ \\
Saving & 0.1699 & 0.2301 & 0.1555 & 0.1798 & 0.1979 & 0.1290 & 0.1733 \\
$\beta_{S}, \delta_{j} \beta_{S}$ & $(0.0179)$ & $(0.0542)$ & $(0.0359)$ & $(0.0236)$ & $(0.0455)$ & $(0.0431)$ & $(0.0230)$ \\
Durables & 0.0207 & 0.0158 & 0.0091 & 0.0282 & 0.0106 & 0.0577 & 0.0156 \\
$\beta_{C_{d}}, \delta_{j} \beta_{C_{d}}$ & $(0.0032)$ & $(0.0099)$ & $(0.0052)$ & $(0.0044)$ & $(0.0069)$ & $(0.0098)$ & $(0.0037)$ \\
Prices & 0.0293 & 0.0513 & 0.0282 & 0.0346 & 0.1107 & -0.0236 & 0.0122 \\
$\beta_{P}, \delta_{j} \beta_{P}$ & $(0.0139)$ & $(0.0367)$ & $(0.0280)$ & $(0.0191)$ & $(0.0297)$ & $(0.0515)$ & $(0.0166)$ \\
Population & 0.0783 & 0.0470 & 0.0269 & 0.1187 & 0.0682 & 0.2796 & 0.0473 \\
$\beta_{L}, \delta_{j} \beta_{L}$ & $(0.0094)$ & $(0.0205)$ & $(0.0122)$ & $(0.0140)$ & $(0.0149)$ & $(0.0353)$ & $(0.1065)$ \\
Unshared & 0.1161 & 0.1280 & 0.0747 & 0.1325 & 0.1301 & 0.1533 & 0.0912 \\
$\beta_{U}, \delta_{j} \beta_{U}$ & $(0.0162)$ & $(0.0458)$ & $(0.0333)$ & $(0.0213)$ & $(0.0340)$ & $(0.0549)$ & $(0.0162)$ \\
Observations & 900 & 162 & 144 & 594 & 180 & 198 & 522 \\
\hline
\end{tabular}

This table provides estimates of $\mathbf{y}_{i, t}=\sum_{k} \boldsymbol{v}_{k, t}+\sum_{k} \boldsymbol{\beta}_{k} d_{k, i} y_{i, t}+\boldsymbol{\eta}_{i, t}$, where alternately $k=$ low-income, high-income, and other income, and $k=$ rural, urban, and neither rural nor urban, using annual data from 1997 through 2015; robust standard errors are clustered at the state level and reported in parentheses

the smoothing channels of the groups. The results are discussed in footnotes 13,36 , and 37 .

Acknowledgements We thank two anonymous referees and the editor for their thoughtful suggestions. We are also grateful to Jonathan Swarbrick and Christoph Thoenissen for their comments, and we thank the seminar participants at the Owen School of Management, the Central University of Finance and Economics in Beijing, the Nanjing University of Finance and Economics, and the University of Cyprus, and the participants in the Theories and Methods in Macroeconomics Conference in Nuremburg, and the Royal Economics Society meetings in Warwick. For financial support, we thank the Owen Graduate School of Management and the Leavey School of Business.

Open Access This article is licensed under a Creative Commons Attribution 4.0 International License, which permits use, sharing, adaptation, distribution and reproduction in any medium or format, as long as you give appropriate credit to the original author(s) and the source, provide a link to the Creative Commons licence, and indicate if changes were made. The images or other third party material in this article are included in the article's Creative Commons licence, unless indicated otherwise in a credit line to the material. If material is not included in the article's Creative Commons licence and your intended use is not permitted by statutory regulation or exceeds the permitted use, you will need to obtain permission directly from the copyright holder. To view a copy of this licence, visit http://creativecommons.org/licenses/by/4.0/. 


\section{References}

Alesina A, Tabellini G, Trebbi F (2017) Is Europe an optimal political area? Brookings Papers on Economic Activity, Washington

Altig D, Auerbach AJ, Higgins PC, Koehler DR, Kotlikoff LJ, Leiseca M, Terry E, Ye Y (2019) Did the 2017 tax reform discriminate against blue state voters? Working Paper 25770, National Bureau of Economic Research

Asdrubali P, Sorensen B, Yosha O (1996) Channels of interstate risk sharing: United States 1963-1990. Quarter J Econ 111(4):1081-1110

Awuku-Budu C, Fallon T, Kublashvili S, Zemanek S (2013) Personal consumption expenditures by state: New statistics for 2016 and updated statistics for 2014 and 2015. Surv Curr Bus 1-11

Bachmann O, Gründler K, Potrafke N, Seiberlich R (2019) Partisan bias in inflation expectations. Public Choice 121(553):678-706

Basile R, Girardi A (2010) Specialization and risk sharing in European regions. J Econ Geogr 10(5):645659

Brooks JR (2014) Fiscal federalism as risk-sharing: The insurance role of redistributive taxation. Tax Law Rev 68:89-142

Buti M (2007) Cross-border risk sharing: has it increased in the euro area? Quarter Report Euro Area6 (1)

Calderón C, Chong A, Stein E (2007) Trade intensity and business cycle synchronization: Are developing countries any different? J Int Econ 71(1):2-21

Carbone J, Cahn N (2010) Red Families v. Blue Families: Legal polarization and the creation of culture. Oxford University Press, Oxford

Carlino G, Drautzburg T, Inman RP, Zarra N (2021) Partisanship and fiscal policy in economic unions: Evidence from u.s. states. Working Paper 28425, National Bureau of Economic Research

Chinn MD, Wei S-J (2013) A faith-based initiative meets the evidence: Does a flexible exchange rate regime really facilitate current account adjustment? Rev Econ Stat 95(1):168-184

Cohen L, Coval J, Malloy C (2011) Do powerful politicians cause corporate downsizing? J Polit Econ 119(6):1015-1060

Cornaggia JN, Cornaggia KJ, Israelsen RD (2020) Where the heart is: Information production and the home bias. Manag Sci 66(12):5532-5557

Council for Community and Economic Research (1975) Intercity Cost of Living Index, Quarterly Reports

Dao M, Furceri D, Loungani P (2017) Regional labor market adjustment in the United states: Trend and cycle. Rev Econ Stat 99(2):243-257

Doyle B, Faust J (2005) Breaks in the variability and comovement of g-7 economic growth. Rev Econ Stat 87(4):721-740

Du J, He Q, Rui OM (2011) Channels of interprovincial risk sharing in China. J Comp Econ 39(3):383-405

Feyrer J, Sacerdote B (2013) How much would US style fiscal integration buffer european unemployment and income shocks? (a comparative empirical analysis). Am Econ Rev 103(3):125-128

Furceri D, Loungani P, Pizzuto P (2020) Moving closer? comparing regional adjustments to shocks in emu and the united states. J Int Money Finance

Gelman A, Park D, Shor B, Cortina J (2010) Red state, blue state, rich state, poor state: Why americans vote the way they do (Expanded Edition). Princeton University Press, Princeton

Giannone D, Lenza M, Reichlin L (2010) Business cycles in the euro area. In: Europe and the Euro, NBER Chapters, pp 141-167. National Bureau of Economic Research, Inc

Glaeser EL, Ward BA (2006) Myths and realities of american political geography. J Econ Perspect 20(2):119-144

Helpman E, Razin A (1978) Welfare aspects of international trade in goods and securities. Quarterl J Econ 92(3):489-508

Hepp R, von Hagen J (2013) Interstate risk sharing in germany: 1970-2006. Oxf Econ Pap 65(1):1-24

House C, Proebsting C, Tesar L (2019) Quantifying the benefits of labor mobility in a currency union. Working paper, University of Michigan

Imbs J (2004) Trade, finance, specialization, and synchronization. Rev Econ Stat 86(3):723-734

Jappelli T, Pistaferri L (2011) Financial integration and consumption smoothing. Econ J 121(553):678706

Kalemli-Ozcan S, Papaioannou E, Peydra J-L (2013) Financial regulation, financial globalization, and the synchronization of economic activity. J Finance 68(3):1179-1228 
Kalemli-Ozcan S, Sorensen BE, Yosha O (2003) Risk sharing and industrial specialization: Regional and international evidence. Am Econ Rev 93(3):903-918

Kiewiet DR, McCubbins MD (1985) Congressional appropriations and the electoral connection. J Politics 47(1)

Kose MA, Prasad ES, Terrones ME (2009) Does financial globalization promote risk sharing? J Develop Econ 89(2):258-270. New Approaches to Financial Globalization

Labhard V, Sawicki M (2006) International and intranational consumption risk sharing: the evidence for the United Kingdom and OECD. Bank of England working papers 302, Bank of England

Levitt SD, Snyder JM (1995) Political parties and the distribution of federal outlays. Am J Polit Sci 39(4):958-980

Lewis KK (1996) What can explain the apparent lack of international consumption risk sharing? J Polit Econ 104(2):267-297

Milano V (2017) Risk sharing in the euro zone: the role of european institutions. Mimeo, LUISS School of European Political Economy

Milano V, Reichlin P (2017) Risk sharing across the US and EMU: the role of public institutions. Policy brief, LUISS School of European Political Economy

Mundell R (1961) A Theory of Optimum Currency Areas. Amer Econ Rev

Nakamura E, Steinsson J (2013) Fiscal stimulus in a monetary union: Evidence from US regions. Am Econ Rev 104(3):753-92

Obstfeld M (1993) Are industrial-country consumption risks globally diversified? NBER Working Papers 4308. National Bureau of Economic Research, Inc

Obstfeld M (1994) Risk-taking, global diversification, and growth. Am Econ Rev 84(5):1310-29

Parsley D, Wei S-J (1996) Convergence to the law of one price without trade barriers or currency fluctuations. Q J Econ 111(4):1211-1236

Parsley D, Wei S-J (2016) Fiscal policy shocks and real exchange rates. Working paper, Vanderbilt University

Rangvid J, Santa-Clara P, Schmeling M (2016) Capital market integration and consumption risk sharing over the long run. J Int Econ 103:27-43

Rodríguez-Fuentes C, Dow S (2003) Emu and the regional impact of monetary policy. Reg Stud 37(9):969-980

Stewart C (2012) The Value of committee assignments in Congress since 1994. Working paper. MIT Political Science Department

Stewart C, Woon J (2017) Congressional Committee Assignments, 103rd to 115th Congresses, 19932017: (House, and Senate), 11/17/2017. http://web.mit.edu/17.251/www/data_page.html\#2. Accessed 22 Feb 2019

von Hagen J (1998) Fiscal policy and intranational risk-sharing ZEI Working Papers B 13-1998. University of Bonn, ZEI - Center for European Integration Studies

Publisher's Note Springer Nature remains neutral with regard to jurisdictional claims in published maps and institutional affiliations. 